\title{
Malaysian Food Barometer (MFB): a study of the impact of compressed modernisation on food habits
}

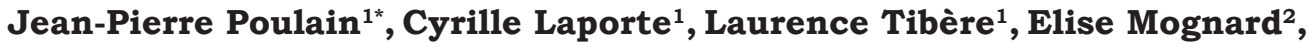 \\ Neethianhantan Ari Ragavan ${ }^{2}$, Anis Ashraf Zadeh ${ }^{3}$ \& Ismail Mohd Noor ${ }^{2}$
}

${ }^{1}$ ISTHIA \& CERTOP UMR CNRS 5044, Université de Toulouse, Taylor's University Malaysia, LIA CNRS Food, Cultures \& Health; ${ }^{2}$ Taylor's University Malaysia, LIA CNRS Food, Cultures \& Health; ${ }^{3}$ Faculty of Social Sciences and Leisure Management, Taylor's University, Malaysia, LIA CNRS Food, Cultures \& Health

\begin{abstract}
Introduction: The Malaysian society is undergoing rapid modernisation. The emerging middle class in Malaysia is influencing the lifestyles and traditional food habits of the main three ethnics (i.e. Malays, Chinese, and Indians). This article studied the impact of compressed modernisation on food in a multicultural context. The Malaysian Food Barometer (MFB), published in the year 2014, focuses on the socio-cultural determinants of food habits in Malaysia. Methods: The methods applied in the study were qualitative and quantitative surveys of the food barometers developed at the national level to study the transformation of eating habits. The surveys studied the socio-economic, demographic, and cultural determinants of food consumption, as well as identifying their possible influences on health issues. Results: The results showed two major distinguishing characteristics of Malaysian food patterns, i.e. linking with Malaysia's multi-ethnicity background and the high frequency of foods consumed outside of home by the urban population. Conclusion: The article concluded that like many societies in transition, Malaysia has to face a rise in the prevalence of overweight. However, with its multicultural characteristics, it becomes a privileged empirical field of observation for the analysis of modernisation modalities of diet models among different ethnic groups.
\end{abstract}

Keywords: Compressed modernity, eating out, social norms, meal, food cultures, food studies

\section{INTRODUCTION}

The Malaysian society is facing a rapid modernisation. From 1970, when the middle class started emerging (Shamsul, 1999; Embong, 2002; Embong, 2007), the traditional ways of life of the different national ethnic communities started changing. Malaysia has passed from under-nutrition to over-nutrition, and has experienced a transition from mortality rates based on epidemic diseases, whose severity was reinforced by the lack of food, to a higher incidence of mortality through non-transmissible diseases and obesity. According to Shamsul (2012), "What a contrast between the student demonstration over the plight of peasants in Baling suffering from 'hunger and poverty' in 1974, and the establishment twenty years after of

*Corresponding author: Professor Jean-Pierre Poulain

Chair of Food Studies, Taylor's University, 1 Jalan Taylor's, 47500, Subang Jaya

Selangor Darul Ehsan, Malaysia

Tel: (+33)675145841; E-mail: poulain@univ-tlse2.fr

doi: https://doi.org/10.31246/mjn-2019-0042 
the Malaysian Association of the Study of Obesity (MASO), concern over the increase of obesity and other related non-communicable diseases (NCDs) medical problems".

Furthermore, nutritional surveys have been scrutinising these transformations for many years. Tee $(1980,1994)$ published an annotated comprehensive bibliography of nutritional research from 1900 to 1993. After 1993, research on nutrition in Malaysia intensified (Tee, 1999; Ismail, 2002) and culminated with the Malaysian Adult Nutrition survey (MANS) in 2003, which was based on a national representative sample (MOH Malaysia, 2008a; MOH Malaysia, 2008b). The scientific production of nutritional studies on specific populations continued at a steady level among women (Karupaiah et al., 2012), minorities in Peninsular Malaysia (Khor \& Zalilah, 2008; Gan et al., 2011), as well as in Sabah and Sarawak (Py et al., 2012). A new Global Nutrition Survey has been launched by the Ministry of Health $(\mathrm{MOH})$ Malaysia. All these research projects focus mainly on the food intake of individuals, evaluated in terms of nutrient composition (macroand micro-nutrients), with some ethnic dimensions included.

Simultaneously, one could find a body of ethnographic and anthropological literature on the food habits, beliefs, and taboos relating to the Malaysian indigenous Orang Asli population (i.e. originally mountainous jungle dwelling hunter-gatherers, mainly the Senoi and Negrito groups) (Bolton, 1972; Lim \& Chee, 1998), besides specific times in their life cycle such as pregnancy and confinement(Manderson, 1981). Previous studies on nutrition have already paved the way in this direction (Ismail, 2002; Rampal et al., 2007; MOH Malaysia, $2008 b)$. Adaptation of food pyramids to local cultures has been undertaken, however, the impact is largely unknown and needs to be evaluated. Nevertheless, a survey which focuses on the sociocultural determinants of food habits at the national level has been missed. Therefore, the aim of the Malaysian Food Barometer (MFB) is to fill this gap. MFB studies the social, ethnic, and cultural diversification of food habits in Malaysia. It also investigates the evolution of food consumption, both at home and outside the home, and identifies the consequences in terms of market factors and public health.

In addition, this study is based on the empirical data from a research conducted in 2012 - 2014 as part of the 'Food Studies Chair: Food, Cultures and Health' in collaboration with Taylor's University (Malaysia) and the University of Toulouse Jean Jaurès (France). In this article, after discussion about the effects of modernisation on the Malaysian society, we present the methodology used and the objectives of the MFB. Next, we expose some of the results relating to two main characteristics of the Malaysian food model. Finally, we discuss about how the theory of 'compressed modernisation' explains the Malaysian situation.

\section{Understanding the effects of modernisation in a multicultural context}

The main objective here is to analyse the effects of the very fast modernisation (what is called "compressed modernisation") on food cultures and practices of different Malaysian ethnic groups. The process of modernisation in Malaysia is characterised by rapid urbanisation and rural exodus. The urban population increased from 11\% in 1951 to $51 \%$ in 1991, and from $62 \%$ in 2000 to $73 \%$ in 2012 (Jaafar, 2004; BMCE trade, 2013), which was accompanied by the industrialisation of the New Economic Policy Era in 19711990 (Aziz, 2012) and the development 
of the services economy from 1970 (Hutton, 2003).

Furthermore, at stage three of the demographic transition model (DTM), which is characterised by a drop in birth rate, the structure of the Malaysian society is changing. The fertility rate decreased from 3.29 children per woman in 2000 to 2.64 in 2012 (Index Mundi Malaysia, 2013), and the size of household being reduced from the average 5.2 persons in 1980 to 4.3 in 2010 (Sudha, 1997; Mahari et al., 2011). The increase in purchasing power of newly waged and salaried employees is an additional factor that is combined with the reduction in family size to herald the emergence of a new middle class (Shamsul, 1999; Embong, 2007), as well as a new working class with greater ability to participate in the consumption economy.

Moreover, related epidemiological transition has modified the causes of mortality from epidemic diseases to cardiovascular diseases, cancers, and degenerative diseases. The success of modern medicine in understanding and taming these diseases points out that lifestyles and food habits are levers, both for prevention and for care. The life expectancy has gained 3.2 years in 12 years between 2000 and 2012 (Ismail, 2002; Index Mundi Malaysia, 2013). Therefore, the current obesity epidemic in Malaysia and worldwide raise concerns about the negative effects of such transformations, and stimulate us to focus research on identifying those factors in the food cultures and lifestyles leading to the development of this issue. All these macro structural developments have affected the lifestyles and the food habits of various ethnic groups which make up the Malaysian population. Hence, we can speak about a stage of food modernity in Malaysia which can be regarded as a consequence of the modernisation of the Malaysian society.
This stage is characterised by the transformation of food intake patterns besides the new consumer expectations and aspirations in relation to food.

In addition, most of the above characteristics can also be found in modern countries. Nevertheless, the Malaysian food consumption context has two major distinct characteristics.

The first characteristic is linked with Malaysia's multi-ethnicity background and the Malaysian society, which consists of four groups. However, the Malaysian society is much more complex than the official organisation of these four main groups and three main ethnic groups (i.e. Malay, Chinese, and Indian, besides a few minorities). As a matter of fact, each group has its own food culture with its typical dishes and ingredients, dietary taboos and restrictions, dining rituals, form and structure of meals, and symbolic 'racial' dimensions of food, which are not totally homogenous in Malaysia. However, 'racial' categories are not homogeneous in Malaysia. For example, Indians may belong to different religions. They may be Hindus, Muslims, Sikhs, Buddhists, Christians, or members of the New Religious Movements. They may speak in Bahasa Malaysia as the national language of Malaysia, English, and different mother tongues (e.g. Tamil, Hindi, Urdu, and Malayalam). They may also be identified strongly by a Caste (different regions of India) or by the neighbouring countries of India where they come from such as Pakistan and Sri Lanka, and also by their families, who may have lived in Malaysia for several generations or just arrived. In addition, 'Chinese' may be Buddhist, Taoist, Christian, or Muslim converts. They may speak Hakka, Hokkien, Cantonese, Teochew, and Mandarin. They may also be Min people, Hakka, Cantonese, and Wu. Furthermore, there are Malaysians in the official 'others' category such 
as the non-Malay Bumiputra, Dusun, Iban, and Kadazan. We have to add foreigners living in Malaysia to this heterogeneous group, including expats (executives and domestic aids), tourists, and international retirees on the 'second home' programme (Tan \& Ho, 2014).

Furthermore, the boundaries between these three main ethnic groups (or races, which is officially used) are not very hermetic. These groups have a certain 'porosity' resulting from interpersonal relationships across ethnic boundaries through friendship, overlapping of religious affiliation and language competence. This 'porosity' is also resulted from the usage behind the primary 'race' identity, religious conversion, and 'crossbreeding' (multi-ethnic people) from historical institutionalised mixed marriages (e.g. in the Baba-Nyonya community in historic times). In addition, it can also be a result from an actual inter-racial breeding, with or without conversion (Hirschman, 1975; Hirschman, 1987; Clammer, 1980; Tan, 1982), and the rise of individualism within, which Malaysians develop personal preferences in choosing from a wide variety of dietary alternatives. Moreover, there are some 'crossbreeding' among the different food cultures. For example, Nyonya cuisine from the Malacca region is a combination of Chinese and Malay food cultures with some influence from the Portuguese. Some restaurants such as Mamak restaurants, which are originally from Tamil Muslims, are now filled up by consumers of all ethnic groups and make a solid contribution to the development of a 'Malaysian mixed' food culture - that is, some dishes and food practices that are commonly shared by, or are compatible with more than one 'ethnic' groups.

The second characteristic is the high frequency of foods consumed outside of home by the urban population in
Malaysia, which is probably rated as one of the highest in the world (Fournier et al., 2016). The population study (MOH Malaysia, 2008b) revealed a strong positive correlation between the high incidence of food consumed outside of home with the level of urbanisation. As urbanisation increase, the opportunities for Malaysians to eat out have increased tremendously and prices are sometimes lower than homemade meals. The idea that the growth of urbanisation develops a food environment with a higher density of outlets, as well as the consequences of increasing the prevalence of eating out and the outcomes of health is being documented in the Western countries (Obbagy, 2012). In this study, we do not mention that eating out could be globally linked with the rise of obesity. Rather, we assume that there is a typology based on a cluster of practices which structure the ethnic food lifestyles in Malaysia, and some of them are connected with obesity. In addition, the range of practical contexts in which Malaysians consumers are deciding what to eat are very different from those encountered in the West. Therefore, public health programmes developed in Europe and USA cannot be transferred to Malaysia without the risk of facing some sociocultural resistance that consequently would have some counterproductive effects.

Therefore, in this context, MFB is a tool to identify and study in depth the socio-cultural determinants of Malaysian food habits. MFB describes the 'food social space' of the Malaysian population. It also focuses simultaneously on the practices and on the representations of food cultures. The aim of MFB is to understand the food lifestyles and the different food contexts of various Malaysian ethnic groups and 'middle class'. In addition, by using a follow-up survey in this study, we could investigate the longitudinal transformation of 
food habits in Malaysia. Finally, these different sets of data and their analysis could be used to uncover the social infrastructure of Malaysians' eating decisions (i.e. patterns, scenarios, and contexts).

\section{METHODOLOGY}

Food barometers are tools developed under the direction of Jean Pierre Poulain and his team to study the socioeconomic, demographic, and cultural determinants of food consumption. They also try to identify the possible influences of food consumption on health issues, particularly NCDs, where diet is involved. In addition, food barometers complement traditional nutritional surveys and aim to participate in the development of prevention programmes (Poulain 2001; Poulain et al., 2010; Poulain et al., 2015; Fournier et al., 2016). They are also qualitative and quantitative surveys developed at the national level to study the transformation of eating habits.

MFB uses a mixed-mode approach, both qualitative and quantitative methods. The questionnaire developed from the outcomes of a qualitative exploratory phase (face-to-face interviews and a focus group) aims to identify the main trends in Malaysian food practices and representations. The questionnaire is organised into six parts: the socio-demographics and ethnic indicators, food norms, diet recall of the last 24 hours, cooking practices, social representations regarding food, and the perception of food and health-related risks. The questionnaire comprises of 66 items with more than 1400 variables including body mass index (BMI). There are 46 closed and multiplechoice questions, consisting of standard questions used in sociology to describe the socio-demographics of a population, as well as questions that have been used in previous food studies (Poulain, 2002;
Poulain et al., 2010) but adapted to the Malaysian context. The questionnaire was translated into three languages (Malay, Chinese, and English) and then retro-translated. All interviewers $(n=42)$ employed for administering the questionnaire were fluent in English, in addition to at least one (other) language to which the questionnaires had been translated. Six interviewers were trained for two days. The purpose of this was to present the structure of the questionnaire and to validate the data collection method. The sample size was 2000 participants of $\geq 15$ years old, estimated using power calculation (Ali \& Azlan Abdullah, 2012; Fournier et al., 2016). The sampling methodology was of a semi-randomised approach based on the regions within Malaysia and their degree of urbanisation. A quota system based on age and ethnicity was also applied. Quantitative data were collected from January to May 2013.

Furthermore, MFB studies eating habits through the socio-anthropological approach to establish an interdisciplinary dialogue with nutrition for public health benefit. The analysis of socio-cultural determinants of meal structures, days, and dietary patterns enriches the approach in terms of individual dominant decision-making in the field of nutrition and health (Fischler, 1990; Warde, 2005; Poulain, 2017).

\section{Operational objectives}

The purpose of the MFB is to draw a picture of the Malaysian food habits to study their diversity based on sociocultural determinants. MFB describes the food habits and food cultures at different dimensions, such as practices, social norms, social representations, and beliefs. These dimensions analyse the effects of social status, level of education, ethnicity, gender, generation, and size of the household and urbanisation. It also measures the importance of eating out 
and prevalence of using convenience food. MFB identifies the food lifestyles with a special focus on the role of ethnicity in the middle class. In addition, it studies the correlation between lifestyle, social characteristics, and body size (i.e. obese and overweight). These data facilitate a comparative analysis between different stages in Malaysia's history and economic development, and between different countries as well.

Therefore, the operational objectives of MFB are to produce useful data for different categories of stakeholders. These stakeholders include: 1. The public health stakeholders (from epidemiologists to those engaged in health and nutrition education), 2. The economic stakeholders (including agro- food chain stakeholders, restaurants, and foodservice industries), and 3 . Academics, who work in the different disciplines and are interested in food consumption and food cultures from anthropology to sciences of nutrition. Figure 1 shows the general objectives of the MFB.

\section{Scientific objectives}

The main scientific objective of the MFB is to challenge the theories of 'convergence' (Mahbubani, 2013), which suggested that with economic development and the emergence of the middle class, food consumption patterns are less determined by sociocultural factors (in Malaysia, ethnicity) than the consumption culture, which is

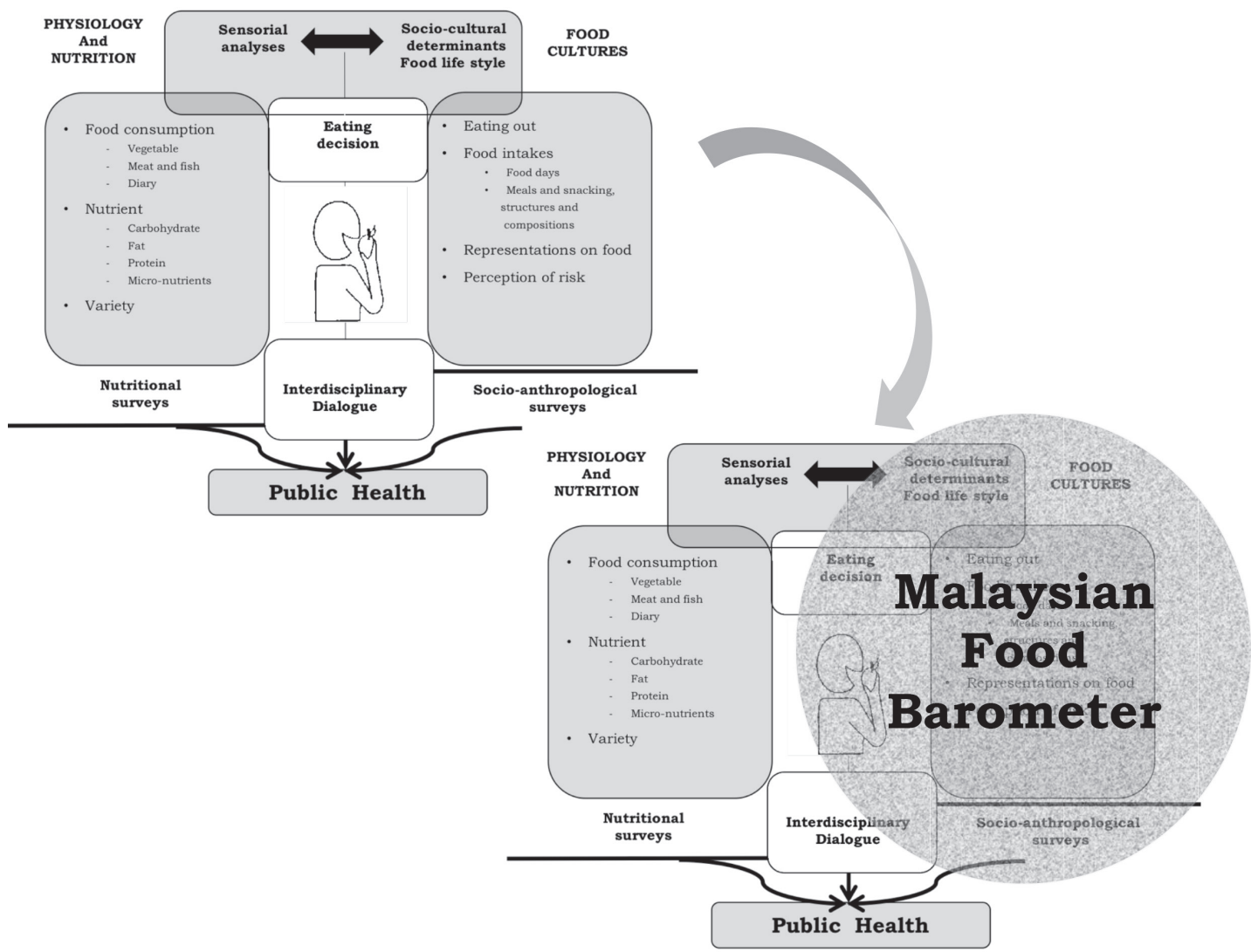

Figure 1. General objectives of the Malaysian Food Barometer (MFB) 
the distinctive feature of middle class. The stage of convergence should be the homogenisation of middle-class lifestyles. Therefore, this study seeks to answer the question of "what is the significant role of ethnic factors within the middle-class conventions of food consumption?'. In addition, as said above, food habits are strongly determined by culture, religion, and social beliefs, therefore, a detailed empirical study seeking rich qualitative data is a meaningful exercise here.

Furthermore, the MFB focuses on food habits at two different levels, i.e. national level and international level. At the level of the Malaysian social and ethnic groups, the survey considers the following questions: 1 . Is there a homogenisation of the Malaysian lifestyle across ethnicity and social positions? 2. What are the consequences of food consumption for frequenting restaurants, casual food stalls, and buying takeaway food? and 3 . What is the connection between these practices and the development of obesity in Malaysia? At the international level, the survey considers: 1 . Is there a convergence of food consumption models through the process of economic development (e.g. is there an increase in foods of animal origin in the daily diet)? 2 . How can we describe and understand the concept of inertia in relation to food cultures? and the main question, 3. How can we understand and model a culture's inertia in the transformation of food habits?

\section{DISCUSSION AND CONCLUSION}

\section{Studying the importance of eating out in the Malaysian daily practices}

Two types of data are available within the Malaysian context. The first type of data are produced by economists, and are interested in the locations where the act of purchase takes place (the central notion is the 'food away from home'). The second type come from surveys and MFB, and report on the food consumption act itself. In this case, we talk about 'eating out' as well. The two types of data are thus not equivalent. In the case of food, 'economic consumption' and 'food consumption' are disconnected in time, and most often are not individualised purchases for home food, while payment and consumption are simultaneous and individualised in the case of 'out of home' catering.

In addition, economists who work on household food budget distinguish the proportion of expenditure on foods consumed at home from foods consumed outside the home. The data mobilised by Lee $\&$ Tan (2007) showed that the share of household 'food away from home' expenditures increased significantly between 1973 (4.6\%) and 1999 (10.9\%). We have aggregated to their data more recent figures $(2009 ; 2014)$ to develop the graph below. Even though these elements are not completely comparable, they do point to a continuous increase in out-of-home diet spending.

Figure 2 shows the expenses of food consumed at-home and outside of home (eating out) as a percentage of total household expenditure. Data for 1973 to 1999 were from Lee \& Tan (2007), while data for 2009 and 2014 were from the Department of Statistics Malaysia (2016).

Furthermore, other works (Ali \& Azlan Abdullah, 2012) centred on the issue of risks (social and health) and the practice of eating out without any nutritional regard, focused on the development of consumption out of home for specific audiences (e.g. students, families, and people in their work places) with observation in some areas of Malaysia such as Bandar Baru Bangi, Jitra and Segamat. This study (however, does not provide the explicit data) explains this movement by factors such as the lengthening of the distance between workplace and home, increase in the 


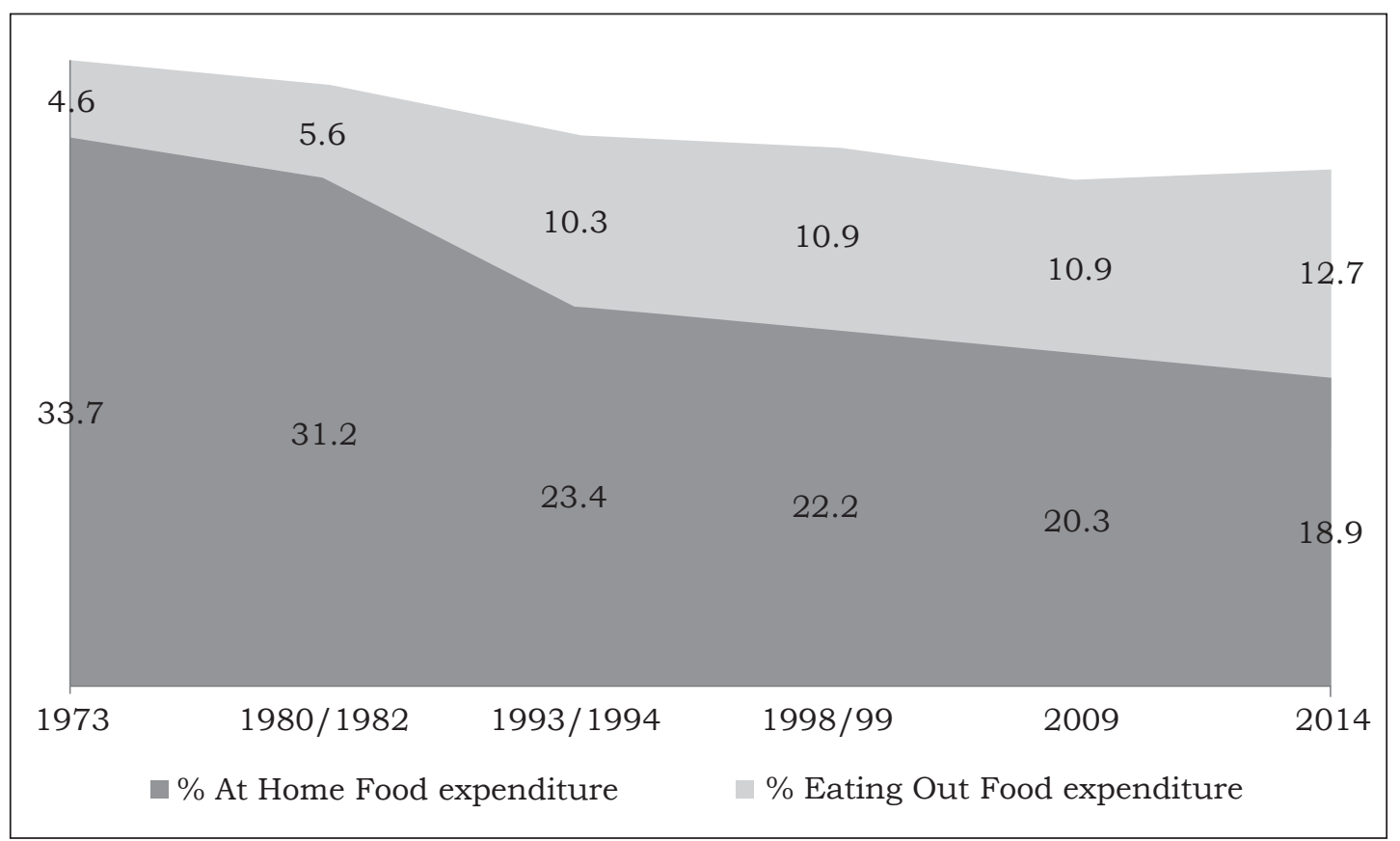

Figure 2. Expenses of food consumed at-home and outside home (eating-out) as a percentage of total household expenditure. Data 1973 to 1999 (Lee \& Tan, 2007); data 2009 and 2014 (Department of Statistics Malaysia, 2014)

work of the 'mothers', and the profusion of food supply in catering. Restaurants not only provide 'meal time' foods, but also provide the opportunity to eat at any time in a variety of contexts (e.g. work meeting and celebration). While the purpose of these analyses is to show the risks (for health, social, and familial) of the development of 'eating out' in dietary practices, they also complete a first panorama that outlines the importance of 'eating out' in Malaysia.

Moreover, in MFB, we used two main indicators to study the 'eating out' practices:

1. Reconstruction of the food taken of the previous week: the value of the weekly intake is 1 when all food consumption is carried out, and the value is 0 when all intakes are consumed at home.

2. The 24-hour recall with: a ratio of 'out-of-home' frequency based on food intake (i.e. the number of intakes out-of-home/total number of intakes) and a frequency ratio per individual (i.e. the number of individuals with at least one 'out of home' intake).

Two perspectives can be used to describe 'eating out': the proportion of meals consumed by the overall population, and the frequency of 'eating out' for individuals. Therefore, $>38.3 \%$ of Malaysian meals (breakfast, lunch, dinner, and supper) are consumed outside of home (Table 1). And if the food consumed at home is added, but the dishes are from outside (meals delivered or purchased as take away, including from Mamak restaurants), the frequency rises to $47.5 \%$. These practices are positively related to the level of urbanisation, i.e. 32.9\% among 
Table 1. Eating out - only meals (breakfast, lunch, dinner)

Eating out practices for meals only

\begin{tabular}{lcccc}
\multirow{2}{*}{\multicolumn{1}{c}{ Type of data }} & \multicolumn{2}{c}{ Meals } & \multicolumn{2}{c}{ Individuals } \\
\cline { 2 - 5 } & $\mathrm{n}$ & $\%$ & $\mathrm{n}$ & $\%$ \\
\hline Total Intakes & 5,566 & 100.0 & 2,000 & 100.0 \\
Eating at least one meal outside & 2,134 & 38.3 & 1,282 & 64.1 \\
Eating at least one meal at home & 3,422 & 61.7 & 1,768 & 88.4 \\
Eating at home but the meal comes from outside & 515 & 9.2 & 455 & 22.7 \\
\hline
\end{tabular}

rural people, compared to $39.7 \%$ for urban dwellers, and $40.2 \%$ for suburban residents (Poulain et al., 2014).

At the individual frequency level, $>64 \%$ of people consume at least one meal per day outside. From these data, we drew a food landscape in which the number of meals eaten outside the home, and imported meals eaten at home are at a relatively high level (22.7\%) (Figure 3$)$.

In addition, an investigation carried out by the $\mathrm{MOH}$ in 2008, associated these practices to the phenomena of urbanisation. The opportunities for Malaysians to go out of their homes to eat have significantly increased as prices are sometimes lower than the costs of homemade meals. Taking into account the main socio-economic developments and the demographic evolution of the Malaysian society, we can predict an increase in 'eating out' practices. Consequently, the 'industry' of catering is a front-line player in the problem of increasing obesity and NCDs (Laporte, 2018). The contexts in which Malaysian consumers decide what to eat considerably differ from Westerners. Therefore, public health programmes, mainly centred on family diet, that
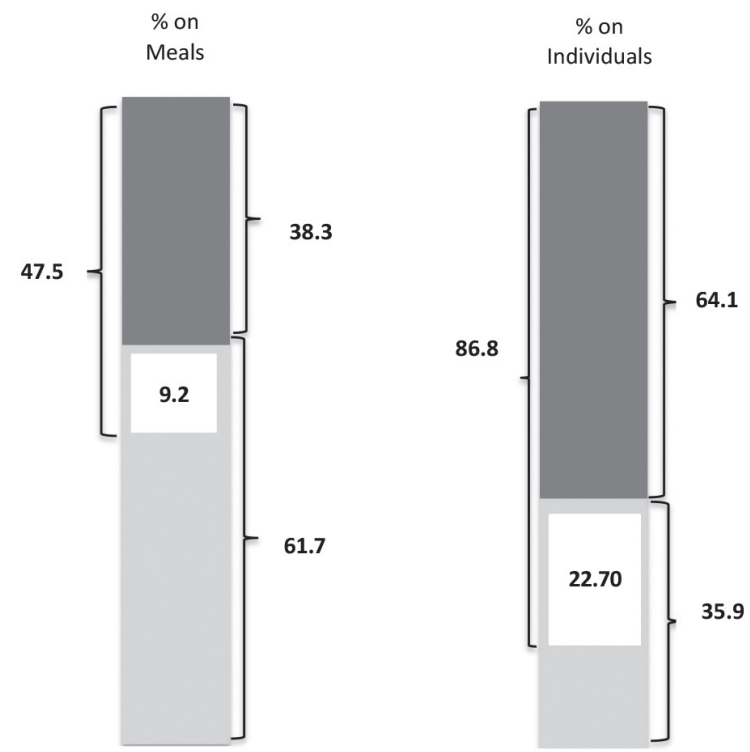

Eating out

Eating at home with meals coming from outside

Eating at home

Figure 3. Eating out in Malaysia - percentage of eating out per meals and per individuals (Poulain et al., 2014) 
are implemented in Europe and the United States cannot be transposed to Malaysia without the probable risk of counterproductive effects.

\section{Individualisation of dietary practices}

Dietary modernity in Malaysia is characterised by an increasing individualisation of food practices noted on several levels, especially the structure of meals. Lévi-Strauss (1963) identified two forms of meal structures. The synchronic form that results in the service of several dishes simultaneously during the same meal, and the diachronic form that results in the service of several dishes, one after another, according to socially predefined rules. The contemporary French meal, which follows a sequence of order 'starters - main dish - cheese dessert', is an example of a diachronic meal in spite of some variations over time and from one social group to another (Fischler, 1990; Poulain, 2002; Poulain, 2017). Some meals are also organised around a main product, which is systematically presented, and is accompanied by other complementary products that may vary from one meal to another. The organisation of a Chinese meal follows the same principle. In other food models, like the French meal, the products are constantly changing. Finally, in the Malaysian society, the level of individualisation is more or less pronounced according to meals (Figure 4).

The process of individualisation is pronounced in 'lunch', where only $27 \%$ of individuals express individual structures and $74.9 \%$ have individualised lunch practices. This dissonance in high norm versus practice (47.9) reflects the individualisation movement. It is similar to dinner where only $18.3 \%$ of respondents express individual structures, whereas $66.2 \%$ of the population implements individualised practices. This strong dissonance between norms and practices (+47.9) points to an attachment to the collective

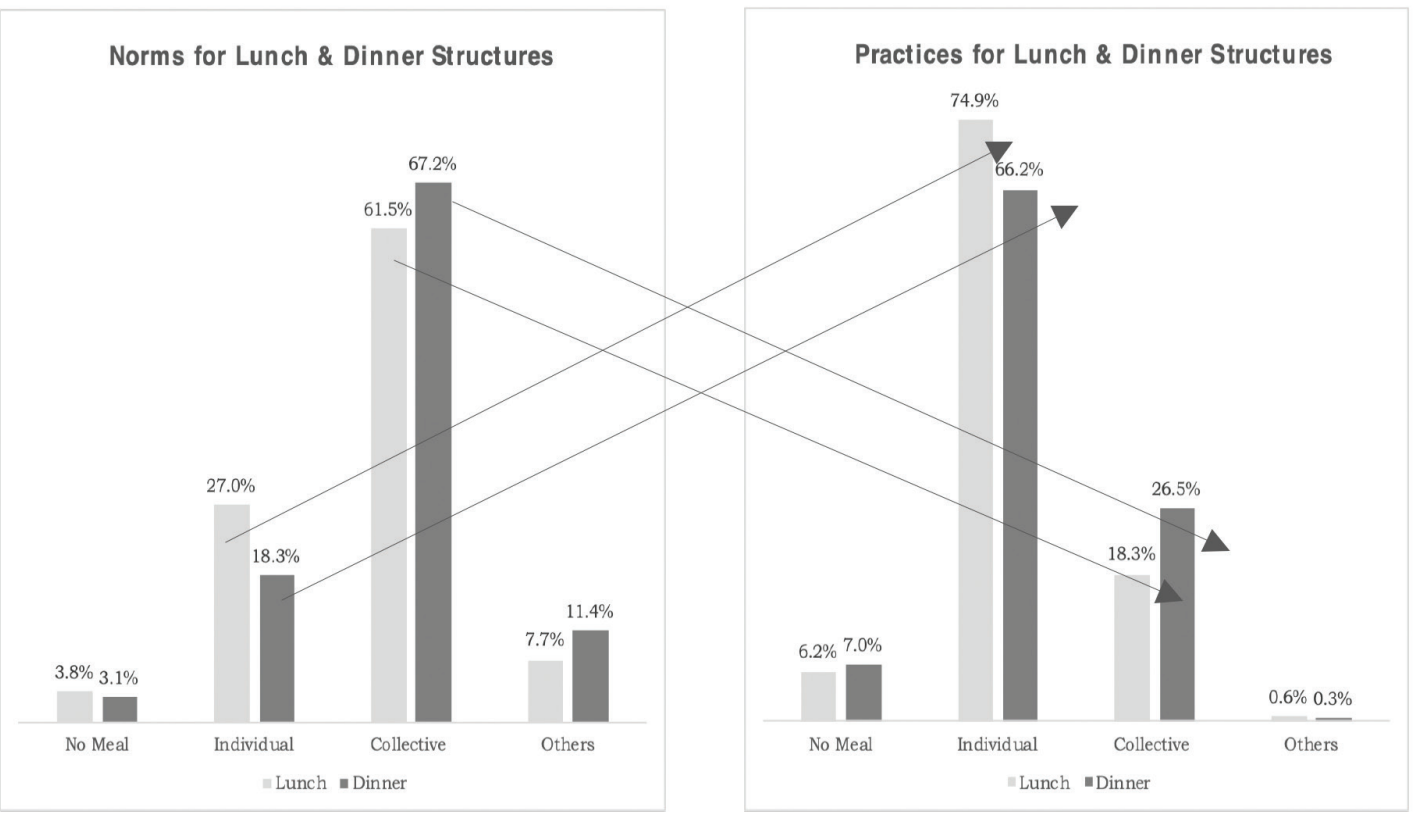

Figure 4. Structure of meals - norms vs. practices (Poulain et al., 2014) 
model in norms coexisting with an individualisation of practices. This situation can be explained by the rapid modernisation of the Malaysian society. However, we observed that certain social groups, such as individuals who live in rural areas or groups like the non-Malay Bumiputras, are hermetic to individualisation, particularly for breakfast. This persistence is also found in individuals with low levels of education at the bottom of the social hierarchy.

The Malaysian food model is therefore characterised by a very high level of eating out and a rapid transformation that focuses on the individualisation of meal structures, mainly for lunch and dinner. This particular context can be relocated in the framework of what some sociologists call 'compressed modernisation' (Chang, 1999; Chang, 2016; Rouleau-Berger \& Neng, 2017; Augustin-Jean \& Poulain, 2018).

\section{A 'compressed' modernisation in Malaysia}

Malaysia is a good example of 'compressed modernisation'. We mentioned above that the middle class emerged during the new economic policy of industrialisation (1971-1990). The traditional lifestyles of different ethnic communities have changed profoundly. In a few decades, Malaysia has shifted from undernutrition to overnutrition, and is now confronted with what public health experts call 'the epidemiological transition' and the 'double burden' of malnutrition (Gillespie \& Haddad, 2003). The first phenomenon is the transition in mortality rates, caused by epidemic diseases and reinforced by food shortage, to deaths from NCDs (e.g. cardiovascular diseases and cancer), in which obesity is a significant risk factor. The second phenomenon, the double burden, is the cohabitation of undernutrition and overnutrition problems within the same population, and at the same time.

The speed of modernisation in some Asian countries has led Korean sociologist, Chang (1999) to propose the concept of 'compressed modernisation', which corresponds to a civilisational context in which economic, political, cultural, and social changes occur in an extremely condensed manner, both in space and time. Also, in which disparate historical and social elements coexist and contribute to the construction and reconstruction of a complex social system characterised by fluidity (Chang, 2016). The compression phenomenon of space and time was described in the mid-1980s by the geographer Harvey (1990). It would be the result of technological innovations developed in the sectors of communication (e.g. telegraph, telephone, fax, and internet), and transport and travel (e.g. highspeed train TGV, democratisation of air transport) which reduces, or sometimes cancels off distances and time. The technological innovations are at the heart of economic development, and help to open up new markets, displace space barriers, speed up production cycles, and reduce capital turnover.

In addition, in the work of Beck and Grand (2010), i.e. articulating theorisation in terms of compressed modernity (Chang, 1999) and the first and second modernity, the authors propose to define it as a situation in which the processes of urbanisation, industrialisation, and economic liberalisation are faster than the transition through a first modernity and the transition to a second modernity which are almost simultaneous. The first modernity corresponds to the rise in rationality and 'de-traditionalisation' of societies. The second one corresponds to a weakening of the legitimacy of 'normative devices', resulting in an 'individualisation of lifestyles' (Beck \& Lau, 2005) and to the post-traditional societies, not in the sense that there is 
no more intergenerational transmission, but in that the normative models have lost their strength and their evidence. The compressed modernity in some Asian countries corresponds to the telescoping of these two forms of modernity.

Furthermore, Chang (1999) describes two sub-phenomena that have an impact on temporal and spatial dimensions, i.e. 'condensation' and 'compression'. Condensation refers to the physical processes required for the movement and change between two moments (epochs), and between two locations (places) to be abridged or compacted. Compression, corresponds to a phenomenon according to which various components of multiple civilisations that existed in different zones and/or places coexist in the same delimited space-time and influence each other. Continuing the reflection on the topic of diet, Poulain (2018a, 2018b) showed that compressed modernity is characterised by the strengthening of the process of patrimonialisation of food cultures, the development of cosmopolitan food cultures, and the rise of some eating anxiety such as:

1. The patrimonialisation of cultural diets: the reduction of time intensifies the designation of 'traditional' food cultures as heritage, and as the central features of the construction and expression of ethnic and social identities. Patrimonialisation is a concept under construction that has opened several heuristic perspectives (Poulain, 2000; Geyzen, 2014; Brulotte \& Di Giovine, 2016; Bessiere, 2018). In Malaysia, this phenomenon is seen with the increase in the number of chain restaurants in major shopping centres, such as Madam Kwan's, Little Penang Café, Secret Recipe, and Old Town White Coffee that meet the need for 'eating out' and give in to nostalgia for heritage at the same time. According to the World Tourism Organization (UNWTO), the number of tourists in Malaysia has made a considerable leap from 5.56 million in
1998 to $>28$ million in 2017 . In addition, domestic tourists are sensitive to food nostalgia. These catering concepts and their 'heritage' food products, loaded with cultural references, seem to benefit from this additional clientele. At the same time, tourists' expectations of local and 'authentic' foods are further accelerating the trend towards the patrimonialisation of foods (Poulain, 1997; Bessière, 2008; Bessière, 2018; Bessière \& Tibère, 2013; Tibère \& Aloysius, 2013; Ramli et al., 2017). This context offers new opportunities for actors in the food industry and the catering sector, enabling them to develop new products and services such as healthy food or foods perceived to have cultural attributes, and to encourage shorter circuits between producers and consumers. It also exposes them to new social responsibilities in the face of the rise of NCDs in which food is a determining factor (Laporte \& Poulain, 2014). Finally, it can be coined in the actions of the Malaysian food culture promotion by the Ministry of Culture and Tourism and in the multiplication of Malaysian cookbooks or the different components of Malaysia (Ibrahim, 1991; Sauw, 2014; Hutton \& Invernizzi Tettoni, 2015; Teong, 2016).

2. Food cosmopolitanism: Malaysia is a multicultural food space where many great cultures, i.e. Indian, Chinese and Malay are mixed and among these big ensembles, other sub-divisions exist depending on the region of origin and religion. The relation to food is also crossed in these diasporic groups by systems of positive and negative tensions with the cultures of origin. With the superposition of different food cultures in the same social space, a food cosmopolitanism develops. Reducing distance in space not only increases the mobility of food and people at the national level (between regions, and between rural and urban areas), but also at the international level (between countries and continents). Mobility develops the 
interconnection or intercrossing of food cultures, and in some contexts their hybridisation or even their creolisation, which constitutes a high degree of cultural cross-fertilisation and creates a new food culture (Tibère, 2016). One of the consequences of the development of tourism and the international hotel industry is to make available on Malaysia the urban territories as an offer to represent the European cultures (e.g. French, Spanish, and Italian), as well as the Asian cultures (e.g. Japanese, Chinese, and Korean), and transnational cultures such as Kentucky Fried Chicken. Kuala Lumpur thus establishes itself in a cosmopolitan universe that sometimes surprisingly mixes different food cultures, such as the advertisement on the front of a restaurant, which displays the expression of 'Italian Tapas'!

3. The rise of food anxiety: food modernity is accompanied by the telescoping of several dimensions likely to be at the origin of crises like the control of frauds, the management of food safety, the sanitary control of food, and the socio-technical controversies related to the used technologies in producing, processing, and marketing of foods (Poulain, 2018b). These different dimensions appear in the West at different times, and develop according to different rhythms. Management and administrative systems were then put in place (ministerial services for fraud repression, health crisis management or food security), and the skills of the populations themselves to choose, prepare, and use food subsequently evolved. In some Asian countries, the dimensions of food crises (fraud, food, and sanitary security and controversies) are simultaneously present and interact with one another to create unique contexts.

Furthermore, MFB data showed the importance of 'out-of-home' consumption practices in the society of Malaysia, which undergoes a compressed modernisation process. MFB is a tool for observing the modernisation of the eating social space of this Southeast Asian society. It describes and follows the food model transformations, especially in the distribution of consumption places and in the process of individualisation practices. The fields of application are numerous, both in health and consumption. For example, regarding the fight against obesity, the prevention models developed in Europe (and extended to the United States), which are based largely on the valorisation of food in the family context, proved to be disconnected from the Malaysian social reality and might even be counterproductive. From the economic point of view, the data highlight an organisation of the food chain in which the relative weight of 'out-of-home' and 'out-of-home food' is especially important. It also points to the importance of social responsibility of 'out-of-home' catering actors from various forms of restoration to their agribusiness suppliers, in addition to the role they are playing in diet-related NCDs. The pattern of food consumption in Malaysia shows that the boundaries between 'out' and 'at home' can emerge in a very different way from the West. This translates, among other things, a variable distribution of weight among the actors in the economy of food Industry. In this particular case, the restaurateur and their devoted sources of supply have a significant weight in the organisation of this activity sector.

Finally, the Malaysian society with its multicultural characteristics (assigned as ethnicities through a long period of positive discrimination policy) arises as a privileged empirical field of observation for the analysis of the modernisation modalities of diet models among different ethnic groups. In other words, it makes it possible to identify changes 
in the relative weight of sociological and cultural variables during modernisation. Malaysia is also a prime location for adapting tools to Chinese, Indian, and Indonesian food cultures. Therefore, MFB is the first step of the current development within the framework of the International Associated Laboratory French National Center for Scientific Research (CNRS): Food, Cultures and Health, an Asian Food Barometer (AFB). More broadly, through the study of these lifestyle mutations, rationale of supply and ways of eating, MFB also offers the opportunity to identify favourable conditions to the emergence of new forms of food crises (Simoulin, 2018; Augustin-Jean \& Poulain, 2018).

\section{Acknowledgements}

This study had the benefit of several unconditional grants from the Ministry of Higher Education, Malaysia, Long Term Research Grant Scheme (LRGS) "The National Social Cohesion Programme" headed by Prof. Datuk Dr. Shamsul Amri Baharuddin (Universiti Kebangsaan Malaysia), the Taylor's University Research Cluster (TURC) Malaysia, the Centre National Interprofessionnel de l'Economie Laitiere (CNIEL) France, Nestle Malaysia, and Coca-Cola Malaysia. The funders had no role in the study design, data collection and analysis, decision to publish, or preparation of the manuscript.

\section{Authors' contributions}

JPP, conceptualised the MFB, organised and supervised its realisation, wrote the first version of the article; CL, participated in the conceptualisation of the MFB, its realisation, the treatment of data and writing the article; LT, participated in the conceptualisation of the MFB, its realisation, the treatment of data and writing the article; EM, participated in the production of the MFB, the treatment of the data and the drafting of the article; NAR, participated in the conceptualisation of the MFB and the proofreading of the article; AAZ, did the scientific revision, proof writing and academic editing of the article; IMN, participated in the conceptualisation of the MFB and the proofreading of the article.

\section{Conflict of interest}

The authors declare that there is no conflict of interest regarding the publication of this article.

\section{References}

Ali N \& Azlan Abdullah M (2012). The food consumption and eating behavior of Malaysian urbanites: Issues and concerns. GMJSS 8(6):157-165.

Augustin-Jean L \& Poulain JP (2018). Risk and Food safety in China and Japan: Theoretical perspectives and empirical Insights. Routledge, London.

Aziz AR (2012). New economic policy and the Malaysian multi-ethnic middle class. Asian Ethn 13(1):29-46.

Beck U \& Lau C (2005). Second modernity as a research agenda: theoretical and empirical explorations in the 'meta-change' of modern society. Br J Sociol 56(4):525-557.

Beck U \& Grand E (2010). Varieties of second: The cosmopolitan turn in social and political theory and research. Br J Sociol 61(3):409-443.

Bessiere J (2008). Eating elsewhere, eating locally: The role of regional gastronomy in tourism. Revue Tourisme 16:155-161.

Bessiere J (2018). Patrimoine alimentaire, patrimonialisation. In JP Poulain, Dictionnaire des cultures alimentaires (pp. 1051-1057). PUF, Paris.

Bessiere J \& Tibere L (2013). Traditional food and tourism: French tourist experience and food heritage in rural spaces. $J$ Sci Food Agric 93(14):3420-3425.

BMCE Trade (2013). In: Malaisie: Introduction. From http: / / www.bmcetrade.co.ma/fr/observerles-pays / malaisie / presentation [Retrieved February 27 2020].

Bolton JM (1972). Food taboos among the Orang Asli in West Malaysia: a potential nutritional hazard. Am J Clin Nutr 72(25): 789-799.

Brulotte RL \& Di Giovine MA (eds) (2016). Edible identities: Food as cultural heritage. Routledge.

Chang KS (1999). Compressed modernity and its discontents: South Korean society in transition. Economy and Society 28(1):30-55.

Chang KS (2016). Compressed modernity in South Korea: Constitutive dimensions, manifesting units, and historical conditions. Routledge Handbook of Korean Culture and Society. Routledge, London \& New York.

Clammer JR (1980). Sociology of the Baba Communities of Malaysia and Singapore. Singapore University Press, Singapore. 
Department of Statistic Malaysia (2016). In: Report on household and income expenditure survey, 2016. From https://www.dosm.gov.my/v1/index. php?r=column / cthemeByCat\&cat $=323 \& b u 1$ id=WnZvZWNVeDYxKzJjZ3RIUVVYU2s2Zz09 \&menuid=amVoWU54UT10a21 NWmdhMjFMM WcyZz09\# [Retrieved February 2020].

Embong AR (2002). State-led modernization and the new middle class in Malaysia. Spinger, Berlin.

Embong AR (2007). New middle classes in Asia. In G Ritzer (ed). The Blackwell encyclopedia of sociology (pp. 3198-3201). Blackwell Publishing, Oxford.

Fischler C (1990). Homnivore (L'): Sur les Fondamentaux de la Biologie et de la Philosophie. Odile Jacob, Paris.

Fournier T, Tibère L, Laporte C, Mognard E, Ismail MN, Sharif SP \& Poulain JP (2016). Eating patterns and prevalence of obesity: Lessons learned from the Malaysian Food Barometer. Appetite 107:362-371.

Gan WY, Nasir MTM, Zalilah MS \& Hazizi AS (2011). Direct and indirect effects of sociocultural influences on disordered eating among Malaysian male and female university students. A mediation analysis of psychological distress. Appetite 56(3):778-83.

Geyzen, A (2014). Food studies and the heritage turn: a conceptual repertoire. Food and History 12(2):67-96.

Gillespie S \& Haddad LJ (2003). The double burden of Malnutrition in Asia. Sage publications, New Delhi.

Harvey D (1990). The Condition of Postmodernity: An Enquiry into the Conditions of Cultural Change. Wiley-Blackwell, New Jersey.

Hirschman C (1975). Ethnic and social stratification in Peninsular Malaysia. The Arnold and Caroline Rose monograph of the American Sociological Association. From https://www.asanet. org/sites/default/files/savvy/members/Rose/Rose_Ethnic. pdf [Retrieved February 27 2020].

Hirschman C (1987). The meaning and measurement of ethnicity in Malaysia: An analysis of census classification. $J$ Asian Stud 46(3):555-582.

Hutton TA (2003). Service industries, globalization, and urban restructuring within the AsiaPacific: new development trajectories and planning responses. Prog Plann 61(1):1-74.
Hutton W \& Invernizzi Tettoni L (2015). The food of Malaysia: 62 easy-to-follow and delicious recipes from the crossroads of Asia. Periplus Editions, Bali.

Ibrahim J (1991). Hawkers delight: a guide to Malaysia \& Singapore hawkers food. S. Abdul Majeed, Kuala Lumpur.

Index Mundi Malaysia (2013). In: Malaysia Demographics Profile 2019. From http:// indexmundi.com/malaysia/demographics_ profile.html [Retrieved February 27 2020].

Ismail MN (2002). The nutrition and health transition in Malaysia. Public Health Nutr 5(1A):191-195.

Jaafar J (2004). Emerging trends of urbanisation in Malaysia. Journal of the Department of Statistics Malaysia 1:43-54.

Karupaiah T, Swee WCS, Liew SY, Ng BK \& Chinna K (2013). Dietary health behaviors of women living in high rise dwellings: a case study of an urban community in Malaysia. $J$ Community Health 38(1):163-171.

Khor GL \& Zalilah MS (2008). The ecology of health and nutrition of "Orang Asli" (indigenous people) women and children in Peninsular Malaysia. Tribes and Tribals (2):66-77.

Laporte C (2018). Les enjeux de la restauration collective. In JP Poulain (ed). Dictionnaire des cultures alimentaires (pp.1051-1057). PUF, Paris.

Laporte C \& Poulain JP (2014). Restauration d'entreprise en France et au Royaume-Uni: Synchronisation sociale alimentaire et obésité. Ethnologie française XLIV (1):93-103.

Lee SHH \& Tan KGA (2007). Examining Malaysian household expenditure patterns on food-awayfrom-home. AJAD 4(1):12-24.

Lévi-Strauss C (1963). Structural Anthropology. C Jacobson \& BG Schoepf (trans.). Basic Books, New York.

Lim HM \& Chee HL (1998). Nutritional status and reproductive health of Orang Asli women in two villages in Kuantan, Pahang. Mal $J$ Nutr $4(1): 31-54$.

Mahari Z, Othman WR, Khalili NMM, Esa S \& Miskiman N (2011). Demographic transition in Malaysia: The changing roles of women. From: http://www.cwsc2011.gov.in/papers/ demographic_transitions/Paper_1.pdf. [Retrieved February 27 2020]. 
Mahbubani K (2013). The great convergence: Asia, the West, and the logic of one world. Public Affairs, New York.

Manderson L (1981). Roasting, smoking and dieting in response to birth: Malay confinement in cross-cultural perspective. Soc Sci Med 81(15):509-520.

MOH Malaysia (2008a). Malaysian Adult Nutrition Survey (2003): Vol 1. Methodology. Ministry of Health, Putrajaya.

$\mathrm{MOH}$ Malaysia (2008b). Malaysian Adult Nutrition Survey (2003): Vol 4. Meal Pattern of Adults Aged 18 to 59 Years. Ministry of Health, Putrajaya.

Obbagy, E (2012). The food environment, eating out, and body weight: A review of the evidence. Nutrition Insight 49.

Poulain JP (1997). Le goût du terroir et le tourisme vert à l'heure de l'Europe. Ethnologie francaise XXVII: 18-36.

Poulain JP (2000). Les patrimoines gastronomiques et leurs valorisations touristiques. In Amirou $\mathrm{R}$. et Bachimon $\mathrm{P}$ (ed). Le tourisme local, une culture de l'exotisme, Le Harmattan, París.

Poulain JP (2001). Manger aujourd'hui. Attitudes, Normes et Pratiques. Toulouse, Privat.

Poulain JP (2002). The contemporary diet in France: 'De-structuration' or from commensalism to 'vagabond feeding'. Appetite 8:1-13.

Poulain JP (2017). Sociology of Food. Eating and the place of food in the society. Bloomberry, London.

Poulain JP (2018a). Beyond weak signal theory: From risk analysis to the management of the alimentary concerns, In L Augustin-Jean, JP Poulain (eds). Risk and Food safety in China and Japan: Theoretical perspectives and empirical Insights. Routledge, London.

Poulain JP (2018b). Anxiety as invariant of human relation to food, In $\mathrm{J}$ Ehlert, FN Katharina, Food Anxiety in Globalising Vietnam. Palgrave Macmillan, London.

Poulain JP (2019). Anxiety as invariant of human relation to food, In $\mathrm{J}$ Ehlert, FN Katharina, Food Anxiety in Globalising Vietnam. Palgrave Macmillan, London.

Poulain JP, Guignard R, Michaud C \& Escalon $H$ (2010). Les repas, Distribution journalière, structure, lieux et convivialité, In H Escalon, C Bossard \& F Beck (eds). Baromètre santé nutrition 2008 (pp. 186-211). INPES, Paris.
Poulain JP, Smith W, Laporte C, Tibère L, Ismail MN, Mongard E, Aloysius M, Ari Ragavan N \& Shamsul AB (2015). Studying the consequences of modernization on ethnic food patterns: Development of the Malaysian Food Barometer (MFB). Anthropology of food (online). From http://journals.openedition.org/aof/7735 [Retrieved February 27 2020].

Poulain JP, Tibère L, Laporte C \& Mongard E (2014). Malaysian Food Barometer. Taylor's University Press, Kuala Lumpur.

Py Lee, Cheah WL, Chang CT \& Siti Raudzah G (2012). Childhood obesity, self-esteem, and health-related quality of life among urban primary school in Kuching, Sarawak, Malaysia, Mal J Nutr 2:207-219.

Rampal L, Rampal S, Khor GL, MD Zain A, Ooyub S, Rahmat R, Ghani SN \& Krishnan J (2007). A national study on the prevalence of obesity among 16127 Malaysians. Asia Pac J Clin Nutr 16(3):561-566.

Ramli AM, Zahari MS, Halim NA \& Aris MH (2017). Knowledge on the Malaysian food heritage. AjQoL 2(5):31-42.

Rouleau-Berger L \& Neng L (2017). Compressed modernity and Chinese temporalities. Temporalités 26. doi: 10.4000/ temporalites.3810.

Sauw B (2014). Best of Malaysian cooking. Marshall Cavendish International, Singapore.

Shamsul AB (1999). From Orang Kaya Baru to Malayu Baru: cultural construction of the Malay 'new rich. In M Pinches (ed.) Culture and privilege in capitalist Asia (pp. 104-128). Routledge, London \& New York.

Shamsul AB (2012). From hunger to obesity: Confronting the social reality of modernity and food habits in Malaysia. A paper for the National Convention on Food Security in Malaysia: Strategies for the Future, Academy of Science Malaysia (ASM), Putrajaya.

Simoulin V (2018). Contemporary food crises: When industrial failure meets state impotence. In L Augustin-Jean \& JP Poulain. Risk and Food in Asia: Perspectives from China and Japan theoretical perspectives and empirical insights. Routledge, London.

Sudha S (1997). Family size, sex composition and children's education: ethnic differentials over development in Peninsular Malaysia. Population Studies: A Journal of Demography 51(2):139-151. 
Tan CB (1982). Peranakan Chinese in northeast Kelantan with special reference to Chinese religion. J Malays Branch R Asiat Soc 55:26-52.

Tan CH \& Ho SB (2014). Tourists, expatriates and international retirees: An empirical evidence from Malaysia. SHS Web of Conferences 12, 01034, EDP Sciences.

Tee ES (1994). Selected annotated bibliography of research public actions and resource materials (1980-1993). Food, nutrition and health promotion in Malaysia. Food Technology Research Centre, Kuala Lumpur.

Tee ES (1980). An annotated bibliography of nutrition research in Malaysia (1900-1979). University of Malaya Press, Kuala Lumpur.
Tee ES (1999). Nutrition of Malaysians: where are we heading? Mal J Nutr 5(1-2):87-109.

Teong OJ (2016). Nonya heritage kitchen: Origins, utensils and recipes. Landmark Books, Singapore.

Tibère L (2016). Food as a factor of collective identity: The case of creolisation. Fr Cult Stud 27(1):85-95.

Tibère L \& Aloysius M (2013). Malaysia as a food-haven destination: The vision and its sustainability. APJIHT 2(1):37-51.

Warde A (2005). Consumption and theories of practice. J Consum Cult 5(2):131-153. 